\title{
Load Characteristics Analysis of 5MW Offshore Wind Turbine
}

\author{
Liqiang An \\ Department of Power Engineering, School of Energy, \\ Power \& Mechanical Engineering \\ North China Electric Power University \\ Baoding, China \\ alq2146@163.com
}

Jiaqi Zhang

Department of Power Engineering, School of Energy,

Power \& Mechanical Engineering

North China Electric Power University

Baoding, China

zhangjiaqi0209@hotmail.com

\author{
Hexiang Zhao \\ Department of Power Engineering, School of Energy, \\ Power \& Mechanical Engineering \\ North China Electric Power University \\ Baoding, China \\ zhx@ncepu.edu.cn
}

\begin{abstract}
During the yaw control, the load characteristics of yaw system are the key issue to influence the safety and reliability of the wind turbine yaw system. In this paper, based on Von Kammon spectal and EDC wind in IEC standard the $5 \mathrm{MW}$ wind turbine generator system model is established considering the impact of gravity load, aerodynamic load and inertia load. The dynamic characteristics of a $5 \mathrm{MW}$ offshore wind turbine are analyzed when yawing used FAST software to study the effects of different wind conditions, yaw speed. The results show that the pitching rate has a great affect to the load on yaw bearing since pitch during the yaw. The fatigue and extreme load fluctuation changed in different turbulent intensity of the wind.
\end{abstract}

Keywords-Component; Wind Turbine Generator, Sliding Yaw System, Yaw Bearing, Load Characteristics, FAST

\section{INTRODUCTION}

Yaw system is a critical part of wind turbine to follow the wind, and it is also an important load bearing part. Sliding yaw system is widely used in MW-class wind turbine because of the high load bearing ability, and there is no brake and hydraulic device, like rolling bearing, in sliding yaw system. But the sliding bearings use the engineering plastic to realize self lubrication function, so it is easy to cause the yaw gear problem.

In recent years, researchers in the world have done some studies on the yaw of wind turbine, including the yaw aerodynamic calculation, the yaw algorithm[1-4], the yaw system structure dynamics analysis[5-6], etc.

\section{MODEL OF 5 MW OFFSHORE WIND TURBINE}

In this paper, NREL 5MW offshore wind turbine was used as an example, the overall technical parameters are as follows: this wind turbine has three blades and a rotor diameter of about $126 \mathrm{~m}$, cut-in speed, rated wind speed, cut-out wind speed are $3.0 \mathrm{~m} / \mathrm{s}, \quad 11.4 \mathrm{~m} / \mathrm{s}, \quad 25.0 \mathrm{~m} / \mathrm{s}$ respectively, support structure is a height of $107.6 \mathrm{~m}$, and a conventional variable-speed, variable blade-pitch-tofeather configuration is used.

\section{A. Blade model}

The total blade length is $61.5 \mathrm{~m}$ and the weight is $17740 \mathrm{~kg}$. When modeling the blade, it is divided into 17 blade elements from blade root to blade tip for integration of the aerodynamic and structural forces. Except the cylindrical section of the blade root and the transition section, the blade uses 5 DU series airfoil and 1 NACA series airfoil along span wise[7], the sectional parameters of blade element center are shown in Table 1.

TABLE I. SECTIONAL PARAMETERS OF BLADE ELEMENT CENTER

\begin{tabular}{ccccc}
\hline Node & $\begin{array}{c}\text { RNodes } \\
(\mathrm{m})\end{array}$ & $\begin{array}{c}\text { Chord } \\
(\mathrm{m})\end{array}$ & $\begin{array}{c}\text { Twist } \\
\text { Angle } \\
\left({ }^{\circ}\right)\end{array}$ & $\begin{array}{c}\text { Airfoil Table } \\
(-)\end{array}$ \\
1 & 11.7500 & 4.557 & 13.308 & DU40_A17 \\
2 & 15.8500 & 4.652 & 11.480 & DU35_A17 \\
3 & 24.0500 & 4.249 & 9.011 & DU30_A17 \\
4 & 28.1500 & 4.007 & 7.795 & DU25_A17 \\
5 & 36.3500 & 3.502 & 5.361 & DU21_A17 \\
6 & 44.5500 & 3.010 & 3.125 & NACA64_A17 \\
\hline
\end{tabular}

Where, RNodes represents the distance from rotor center to blade cross sections along the blade-pitch axis.

\section{B. Support structure model}

Offshore wind turbine support structure typically includes two parts, tower and foundation. Tower is connected to a monopile with the effective density of 8500 $\mathrm{kg} / \mathrm{m} 3$ and the bending stiffness of $1037.14 \times 109 \mathrm{~N} \cdot \mathrm{m} 2$, tower and foundation pile type are shown in Fig. 1. The monopil extends from the tower base down to the mudline, which is $20 \mathrm{~m}$ below mean sea level. 


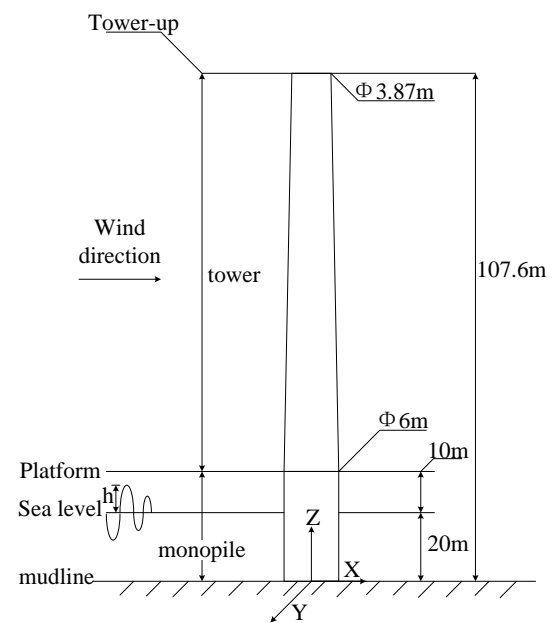

Figure 1. Support structure of offshore wind turbine

Considering the randomness of the waves about time and space, choosing Morrison equation[8] to calculate the wave force, the significant wave height Hs $2.6 \mathrm{~m}$ and wave spectral peak period Tp 5.0s, the significant wave height in time domain is shown in Fig. 2.

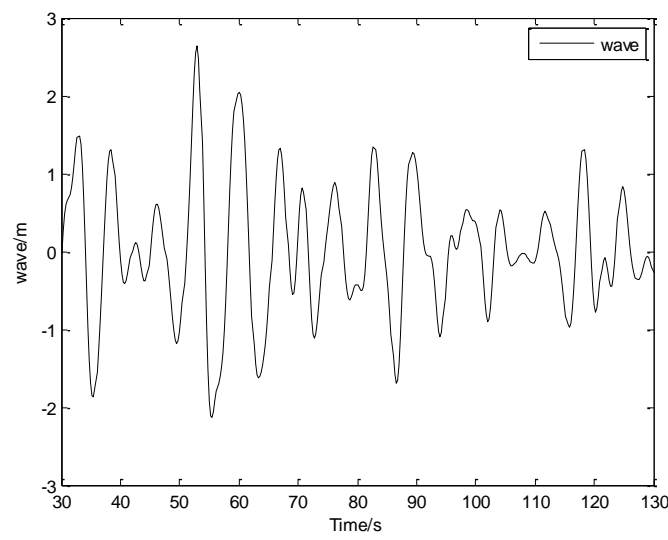

Figure 2. Significant wave height in time domain

\section{Control system model}

For the NREL $5 \mathrm{MW}$ offshore wind turbine, a conventional variable-speed, variable blade-pitch-to feather configuration was chosen, including generatortorque controller and blade-pitch controller. As the wind turbine operates in the section of constant generator power, the generator torque is inversely proportional to the filtered generator speed, so that control system makes the generator speed increase and generator torque decrease. For full-span rotor-collective blade-pitch-angel, the blade pitch control system is chose regulating the generator speed as the goal, adopting the PID controller realize the generator speed control, as shown in Eq.(1):

$$
\Delta \theta=K_{P} N \Delta \Omega+K_{I} \int_{0}^{t} N \Delta \Omega d t+K_{D} N \frac{d \Delta \Omega}{d t}
$$

where $\Delta \theta$ is a small perturbation of the blade pitch angles about their operating point, $\mathrm{KP}, \mathrm{KI}$, and $\mathrm{KD}$ are the blade pitch controller proportional, integral, and derivative gains, respectively, $\Delta \Omega$ is the small perturbation of low speed shaft rotational speed about the rated speed.
After generator failure, wind turbines are forced to pitch-feathering which has a higher priority than the fullspan rotor-collective blade pitch controller. Blades uses a linear ramp from current location to a feathered position for some time, as soon as the rotor speed below a certain value, wind turbines start to break the shaft until the rotor stop.

\section{Yaw system model}

The yaw system is sliding yaw system including control system, yaw mechanism and cable protection device. The yaw mechanism contains yaw generator, yaw speed reducer gearbox, yaw gear and yaw claw. Yaw gear ring is fixed on the top of tower, the yaw reduction box is installed on the bottom of the nacelle. The sliding yaw system is shown in Fig. 3.

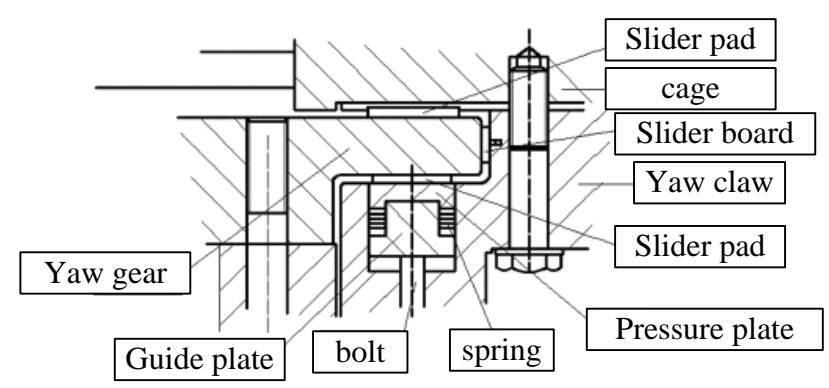

Figure 3. Component of sliding yaw mechanism

As a sensing element, the vane transforms the signal of the wind into electrical signal and transmits it to processor of yaw generator in control loop. Then the processor will compare the signal and judge how to perform yaw motion. In order to reduce gyro torque, yaw generators are connected with the speed reducer gearbox, the yaw moment transmit to yaw gear and drive the wind turbine to yaw. Flow chart of yaw is shown in Fig. 4. When the wind turbine is yawing, the yaw speed is usually fixed, nacelle and yaw claw are connected by bolt. There has sliding friction between yaw claw and yaw gear.

\section{WIND MODEL}

\section{A. Extreme direction change}

The extreme direction change magnitude, ${ }_{e}$, shall be calculated using the following relationship:

$$
\theta_{e}= \pm \arctan \left(\frac{\left(2 \sigma_{1}\right.}{V_{H u b}\left(1+0.1\left(\frac{D}{L}\right)\right)}\right)
$$$$
\sigma_{1}=I_{r e f}\left(0.75 V_{h u b}+b\right), b=5.6_{\mathrm{m} / \mathrm{s}}
$$

where

$I_{r e f}$ is the expected value of the turbulence intensity 2 at $15 \mathrm{~m} / \mathrm{s}$

$V_{H u b}$ is wind speed at hub height;

$\sigma_{1}$ is hub-height longitudinal wind velocity standard deviation; 
$L$ is the turbulence scale parameter;

$D$ is the rotor diameter;

$\theta_{e}$ is limited to the interval 180;

The extreme direction change transient, $\theta(t)$, shall be given by

$$
\theta(t)=\left\{\begin{array}{lc}
0 & t<0 \\
\pm 0.5 \theta_{e}(1-(\operatorname{Ads}(\pi t / T)) & 0 \leq t \leq T \\
\theta_{e} & t>T
\end{array}\right.
$$

Where $T=6_{\text {s is the duration of the extreme direction }}$ change, the sign shall be chosen so that the worst transient loading occurs, at the end of the direction change transient, the direction is assumed to remain unchanged.

\section{B. Turbulence model}

There are two models of turbulence in IEC standard, which are Kaimal model and Von Kamman model. In this paper, we use the Von Kamman model. Energy spectrum function is shown as follow[9]:

where

$$
\left.E(\Omega)=\sigma^{2} \frac{55 L}{9 \pi} \frac{(5)(a L \Omega)^{4}}{1+\left(a L \Omega^{2}\right)^{17 / 6}}\right]
$$

$a=1.33$;

$L$ is the turbulence scale parameter;

$\Omega$ is the space frequency;

$\sigma$ is the turbulence intensity;

Then, the vertical and vertical correlation function of Von Kamman model is shown as follow:

$$
\begin{gathered}
f(\xi)=\frac{2^{2 / 3}}{\Gamma(1 / 3)^{(6))^{1 / 3}} K_{1 / 3}(\xi)} \\
g(\xi)=\frac{2^{2 / 3}}{\Gamma(1 / 3)} \zeta^{1 / 3}\left[(K)_{1 / 3}(\zeta)-\frac{1}{2} \zeta K_{1 / 3}(\zeta)\right]
\end{gathered}
$$

where

$$
\zeta=\xi /(a L)
$$

$\Gamma$ is the Gamma function;

$\mathrm{K}$ is the Bessel function;

\section{LOAD CASE}

The load case is shown in table 2 .

TABLE II. LOADCASE

\begin{tabular}{cccc}
\hline case & $\begin{array}{c}\text { Turbulence } \\
\text { intensity }\end{array}$ & $\begin{array}{c}\text { Wind } \\
\text { speed }\end{array}$ & $\begin{array}{c}\text { Yaw } \\
\text { speed }\end{array}$ \\
\hline 1 & 0 & $13.4 \mathrm{~m} / \mathrm{s}$ & $0.4^{\circ} / \mathrm{s}$ \\
2 & 0 & $13.4 \mathrm{~m} / \mathrm{s}$ & $0.6^{\circ} / \mathrm{s}$ \\
3 & 0 & $13.4 \mathrm{~m} / \mathrm{s}$ & $0.8^{\circ} / \mathrm{s}$ \\
4 & $14.01 \%$ & $13.4 \mathrm{~m} / \mathrm{s}$ & $0.4^{\circ} / \mathrm{s}$ \\
\hline
\end{tabular}

According to the IEC 61400-3 standard[10], choosing the EDC and Von Kamman spectrum to simulate the wind speed, the turbulence intensity was $\mathrm{C}$ and mean wind speed was $13.4 \mathrm{~m} / \mathrm{s}$ at the height of hub, the wind speed of the turbulence at the height of hub center is shown in Fig. 4.

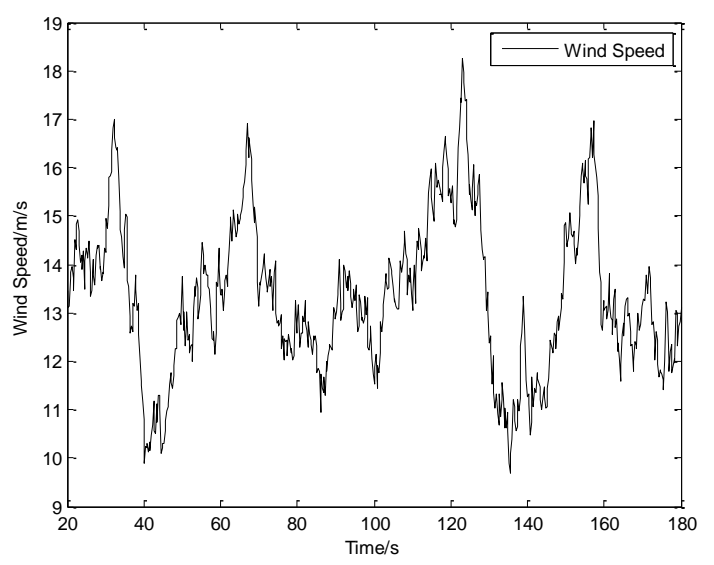

Figure 4. Wind speed of the turbulence at the height of hub center

\section{LOAD CHARACTERISTICS ANALYSIS OF YAW BEARING}

\section{A. Load characteristics of yaw bearing in EDC}

In this paper, FAST was used to simulate the yaw process in normal power generation. The initial wind direction is 0 degrees, vertical to the rotor plane. The wind direction transient occurs at 40.0 seconds, and it occurs over 6.0 seconds. The extreme direction change is 32.72 degrees. At the time, the wind turbine starts to yaw at the speed of 0.4 degrees per second. After 81.8 seconds later, the wind turbine stops yaw maneuver. In the simulation, the wind direction, yaw angle and pitch angle are shown in Fig. 5.

Because of the fluctuation of the power during 20 s to 40 s, the pitch angle has little fluctuation.

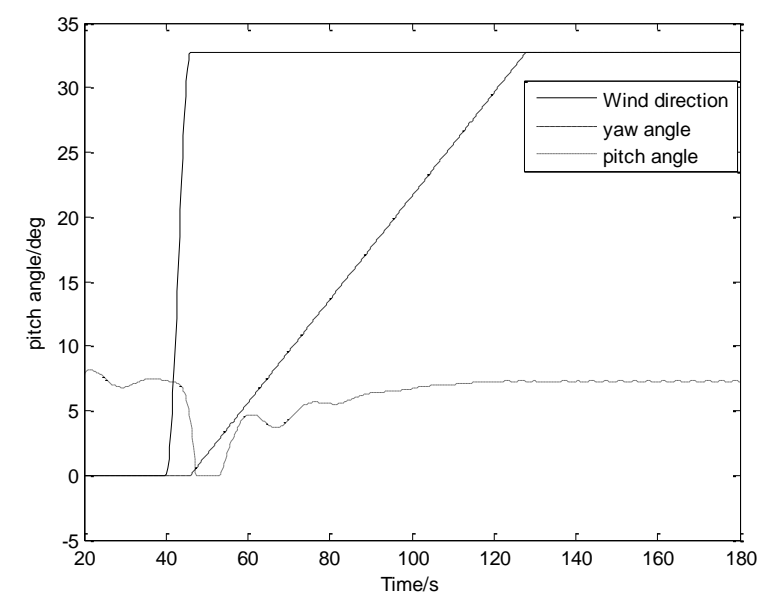

Figure 5. Wind direction, yaw angle and pitch angle in time domain

During the yaw maneuver, the load of the wind rotor and the gravity of the nacelle are transmitted to the yaw mechanism and then transmitted to the tower through the yaw gear. The origin of coordinate system of the yaw bearing load is in the center of yaw gear, which is shown in Fig. 6. $M_{x}$ and $M_{y}$ are overturning moment, which can influence the force between yaw claw and gear, thus changing the friction force of the yaw claw. $M_{z}$ is yaw 
moment. $F_{X}$ and $F_{y}$ are the force along the $\mathrm{x}$ axis and $\mathrm{y}$ axis, which influence the friction force between yaw claw and gear. $F_{z}$ is the force along $\mathrm{z}$ axis, which increases the friction force between yaw claw and gear.

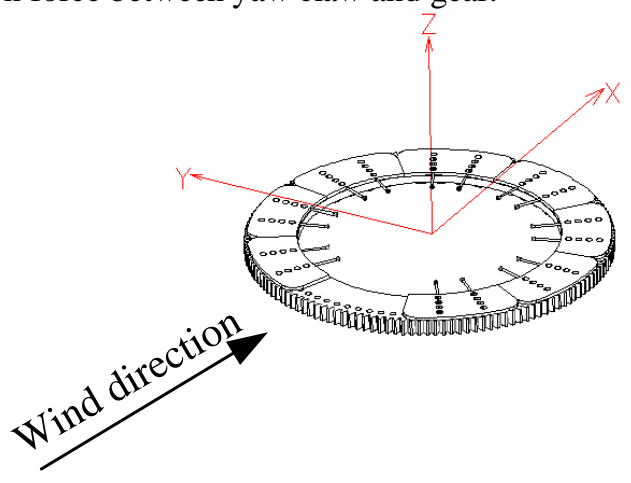

Figure 6. Coordinator of yaw

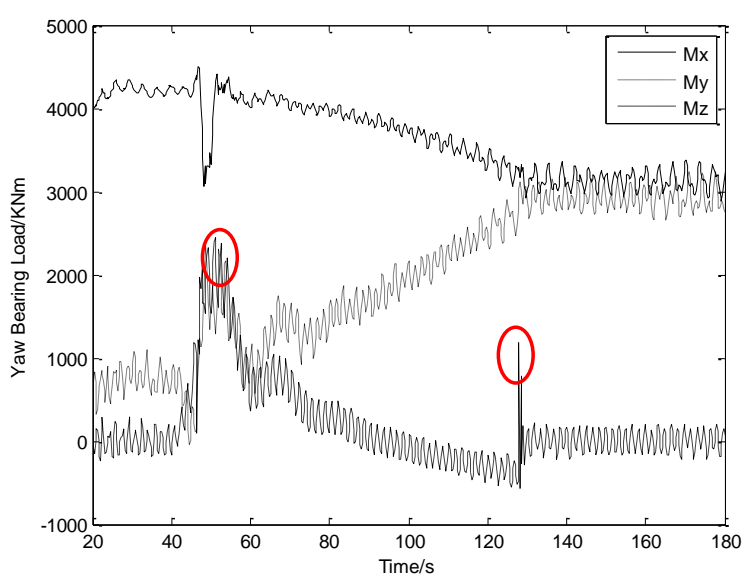

(a) Moment component

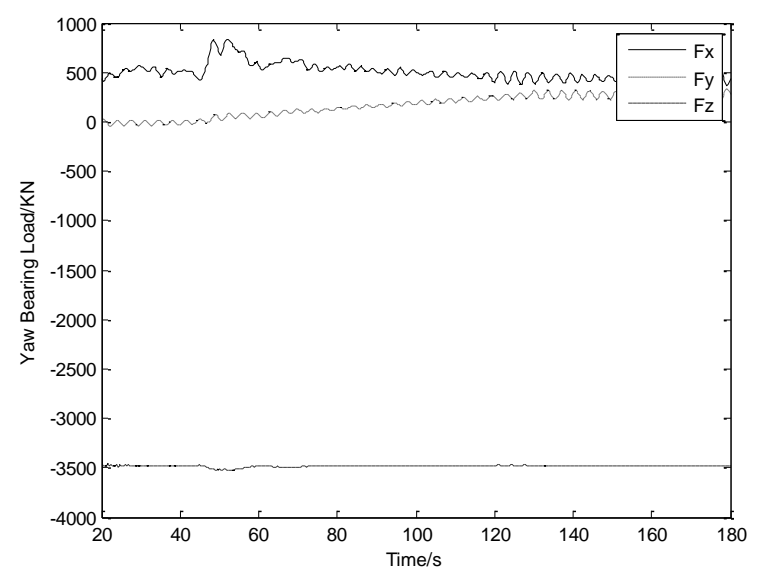

(b) Force component

Figure 7. Yaw bearing load in time domain

According to Fig. 5, the wind direction changed at 40 seconds, in order to keep the maximum power generation, the pitch angle was decrease. In the Fig. 7, the yaw bearing load in time domain is shown in yaw coordinate system. The force along $\mathrm{x}$ axis has increased when the yaw began, and gradually stabilized. The force along $y$ axis has a little increased during yawing. There is almost no fluctuation on the force along $\mathrm{z}$ axis. Consequently, the yaw motion has little influence on the force along $\mathrm{x}$ and $\mathrm{y}$ axis, and it doesn't influence the force along $\mathrm{z}$ axis. It is obviously to see that the moment component have large fluctuations at the time yaw began. The moment along $\mathrm{z}$ axis has a surge at the end of yaw motion. Because the speed of the wind is faster than that of the pitch rate, the power of wind turbine had decrease in a short time when the yaw began, the power curve in time domain is shown in Fig. 8. When the yaw began at $46 \mathrm{~s}$, the angle between wind direction and nacelle became small, the pitch angle increased, the power and the moment were going to stable. Thus, the pitch rate is a important factor to influence the moment of yaw bearing.

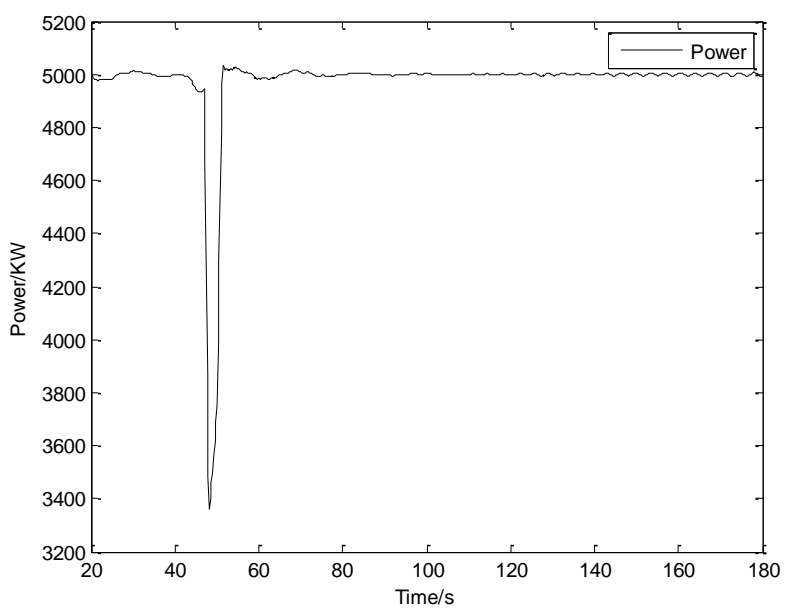

Figure 8. Power in time domain

\section{B. Load characteristics at different yaw speed}

In Fig. 9 and Fig. 10, the yaw bearing loads of case 2 and 3 in domain are shown in yaw coordinate system. Comparing with the load of case 1 , the yaw speed are 0.4 degrees per second, 0.6 degrees per second and 0.8 degrees per second, respectively, it is almost the same between three cases in force component, and it's the same as the moment along $\mathrm{x}$ and $\mathrm{y}$ axis, except the fluctuation time. But there is obvious to see that the moment along $\mathrm{z}$ axis is different. When the yaw began, the maximum moments of three cases are $2441 \mathrm{KNm}, 2215 \mathrm{KNm}$ and $1987 \mathrm{KNm}$, respectively. When yaw was going to stop, the maximum moment of three cases are $1176 \mathrm{KNm}, 1848 \mathrm{KNm}$ and $811.1 \mathrm{KNm}$. It is shown that yaw speed is a important factor to influence the maximum moment in the same wind condition, $M_{z}$ in case 2 at the end of yaw motion is too sharp, it is harm for the life of yaw bearing. It can be seen from the result that the speed 0.8 degrees per second is more fit for this wind condition, it makes the yaw bearing load decreased. 


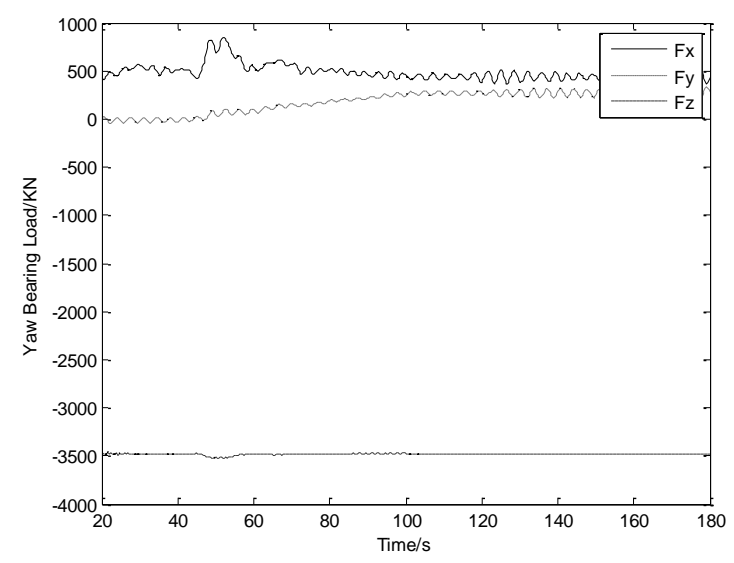

(a) Force component

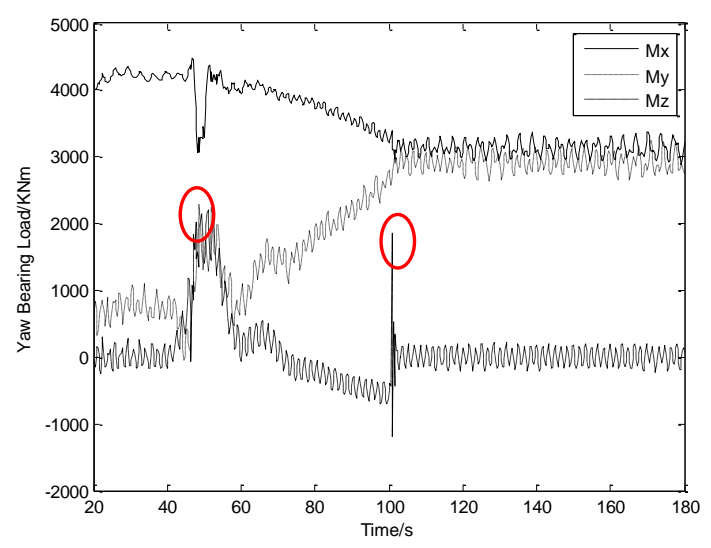

(b) Moment component

Figure 9. Yaw bearing load of case 2

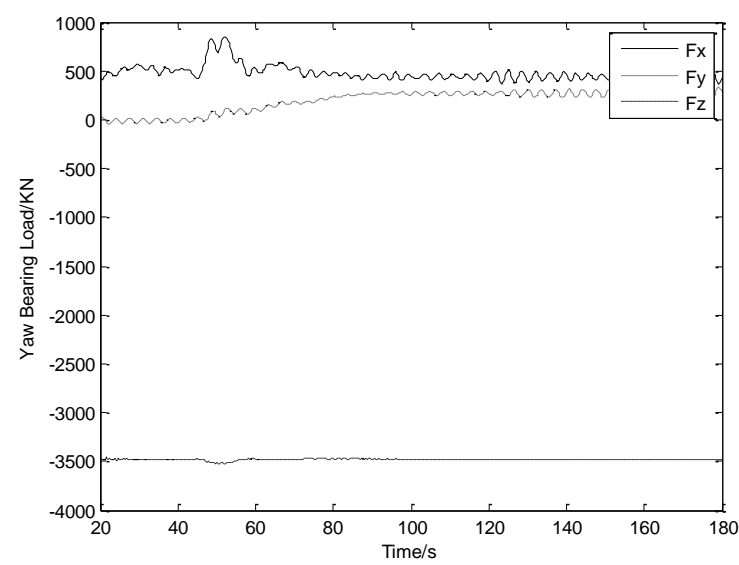

(a) Force component

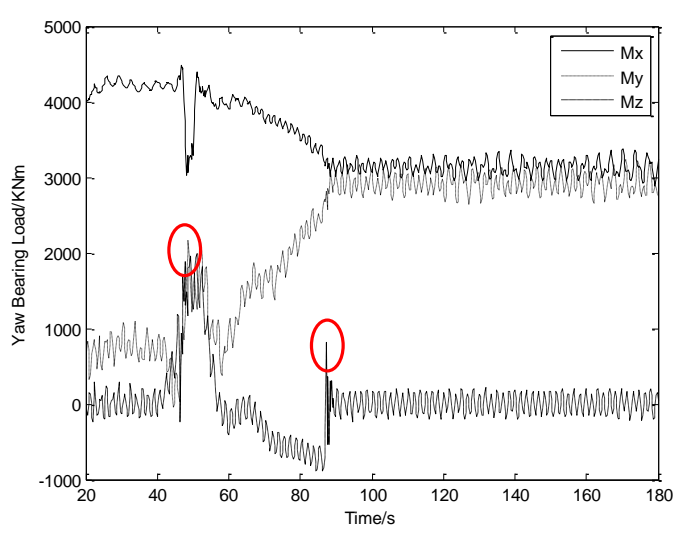

(b) Moment component

Figure 10. Yaw bearing load of case 3

\section{Load characteristics of yaw bearing in turbulence}

In the Fig. 11, the yaw bearing load of case 4 in domain is shown in yaw coordinate system. The force along $\mathrm{x}, \mathrm{y}$ and $\mathrm{z}$ axis fluctuate in a small area. It can be seen that the turbulence has little influence on the force of yaw bearing. But because of the variety of turbulence, the moment component has a big fluctuation. The maximum $M_{z}$ occurs at the time yaw began. The moment's random fluctuation is very large, which shows that the turbulence has a great influence on the fatigue life of the yaw bearing. The peak value of load can be changed by turbulence, and the ultimate load of the yaw mechanism is influenced by it.

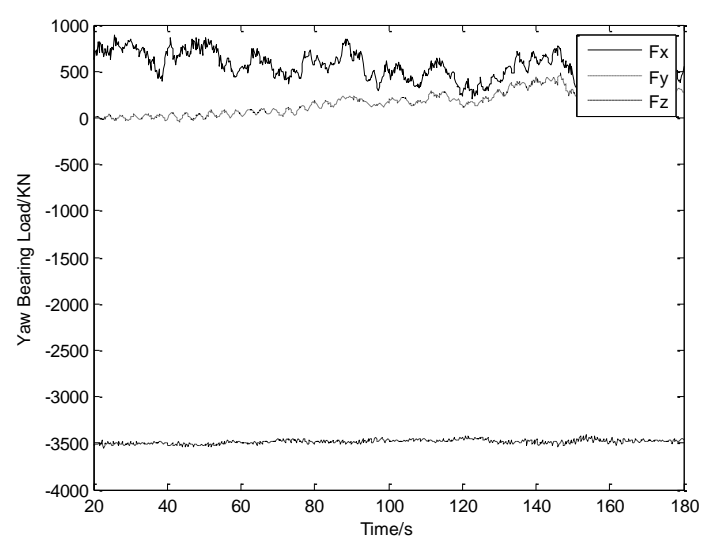

(a) Force component

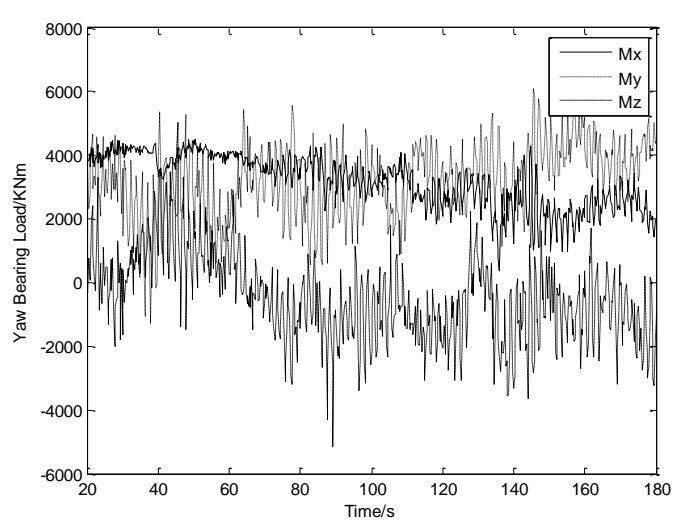

(b) Moment component

Figure 11. Yaw bearing load of case 4 


\section{CONCLUSIONS}

Considering the combined effects of the wind and wave, offshore 5MW wind turbines are chosen as the study object, simulation of wind turbine yaw motion is studied, and it comes to the following conclusions:

The pitch rate is an important factor to influence the yaw bearing load. The load of the yaw bearing can be reduced by controlling the pitch rate. Because the blade load of different conditions is also greatly affected by the variable pitch rate, the choice of the proper pitch rate is an important content of the design of wind turbine.

During the yaw motion, the moment in the three direction of force and the $\mathrm{x}$ direction have little influence of yaw rate and turbulence intensity, $y$ and $z$ direction of the moment have a large fluctuation under the turbulence condition.

The next study is about designing a control system to reduce the yaw bearing load.

\section{ACKNOWLEDGMENT}

This research was supported by the Fundamental Research Funds for the Central Universities (13MS82, 2014ZD33) and Hebei Province Natural Science Foundation (E2013502291).

\section{REFERENCES}

[1] Li Guangming. Study on Antifatigue Mechanism of Wind Power Yaw Drive Reducer. Hunan University, 2011.

[2] E Jiaqiang, Li Guangming, Zhang Bin et al. Fatigue Simulation and Analysis on Planetary Gear of Megawatt Wind Power Yaw Reducer[J]. Journal of Hunan University(Natural Sciences), 2011, 09-32-38.

[3] Niu Linkai. Study on Fatigue Damage of Yaw Bearing in MW Level Winde Turbine[D]. Taiyuan University of Technology, 2011.

[4] Wang Xiuwen. Structural and Dynamics Analysis on the Yaw System of MW Grade Wind Turbine[D]. Chongqing University, 2013.

[5] Yu YI. Performance Analysis and Research of Sliding Yaw Bearing in the Wind Turbine[D]. North China Electric Power University, 2011.

[6] Zhou Fei. Performance Analysis and Research of Yaw Bearing in the Wind Turbine with horizontal axis[D]. North China Electric Power University, 2009.

[7] Zhao Hexiang,An Liqiang,Zou Xingyin,Wang Zhangqi. Twistbend Coupling Analysis for 5 MW Wind Turbine Blades[J].Journal of North China Electric Power University,2013,40(4): 32-36.

[8] Morison J.R et al;The Forces exerted bys-urface waves on piles. Petroleum Transactions, 1950,189(TP2846):149.

[9] Gao Jing, Hong Guanxin, Liang Zaoqing.Theory and method of numerical simulation for 3D atmospheric turbulence field based on Von Karman model[J].Journal of BeiJing University of Aeronautics and Astronautics, 2012,06: 736-740.

[10] International Electro-technical Commission (IEC) IEC 61400-3, Wind turbines part 3: Design requirements for offshore wind turbines[s]. Geneva : International Electrotechnical Commission, 2005 